\title{
Powder Injection Moulding - An Alternative Processing Method for Automotive Items
}

\author{
Berenika Hausnerova \\ Polymer Centre, Tomas Bata University in Zlin \\ Czech Republic
}

\section{Introduction}

Powder injection moulding (PIM) technology represents a challenging production method for automotive items, alternative to machining and investment casting. The European automotive industry utilizes PIM applications over 50\% of the time (Kearns, 2009). In Germany the first Schunk penetrations into the automotive industry were lock caps and lock shafts, followed by cable seals used to fix the cable to car sunroofs, soft magnetic sensor housing parts, cams for electrical adjustment mechanism of car seats, bonnet lock fixing bearings, or rocker arms for VVT engines used by BMW, produced now at an annual rate of 4.5 million pieces. Nowadays, even more stringent parts such as turbocharger vanes, rollers and adjustment rings are produced there (Schlieper, 2007). Concerning ceramics, good application examples are the 8-inch-diameter turbine wheels produced by General Motors for a turbine engine and large static components for automotive gas turbine programs (Moritz \& Lenk, 2009).

Recently, a HYDRO-PIM project in Austria was aimed at developing potential applications for PIM stainless steel for use in extreme low temperatures for BMW Hydrogen 7 (anonym, 2007). Another European project, CarCIM, was initiated in 2006 to develop ceramic components for automotive and railway applications - glow plug, gear wheel, a valve set and braking pads using two-component PIM (Moritz, 2008). Fraunhofer IFAM has coordinated a European project dealing with new material laws for PIM feedstocks called MATLAW to improve feedstock's characteristics and mould filling simulation approaches (Williams, 2009).

Although PIM technology was first commercialized in North America, nowadays Asia is the largest market. The automotive sector remains the largest (19.9 \%) user of PIM parts in Japan (anonym, 2010). The earliest application of PIM in China was an alumina spark plug body for automobile engines in the 1960s (Li, 2007).

During the PIM process, a powder must be at first compounded with a suitable polymer binder to obtain a highly (typically around $60 \mathrm{vol}$. \%) concentrated compound, which is then processed in injection moulding machines utilized in the plastics industry. In the next step, a binder is chemically or thermally withdrawn from the moulded (green) part, and the remaining purely metal or ceramic (brown) part is sintered to its final dimensions and density.

PIM is clearly an interdisciplinary technique combining metallurgy with the processing of plastics. Therefore, products made with PIM technology take advantage of the material 
flexibility of powder metallurgy and the design flexibility of plastics moulding. PIM technology has several advantages in comparison to traditional metalworking as it is a no scrap technique, suitable for designs difficult to machine. German (2007) presented a survey of over 200 PIM components already in production around the world in order to analyze their geometrical attributes and special features such as length, mass, slenderness, wall thickness, number of holes, slots, undercuts, surface texture, e.t.c. and proposed an "ideal" PIM part design (Fig. 1). A great potential of PIM technology is its ability to combine multiple parts into a single item, as for example a drive wheel for a bonnet lock mechanism (Fig. 2), where eight individual parts were combined into one (Schlieper, 2007).

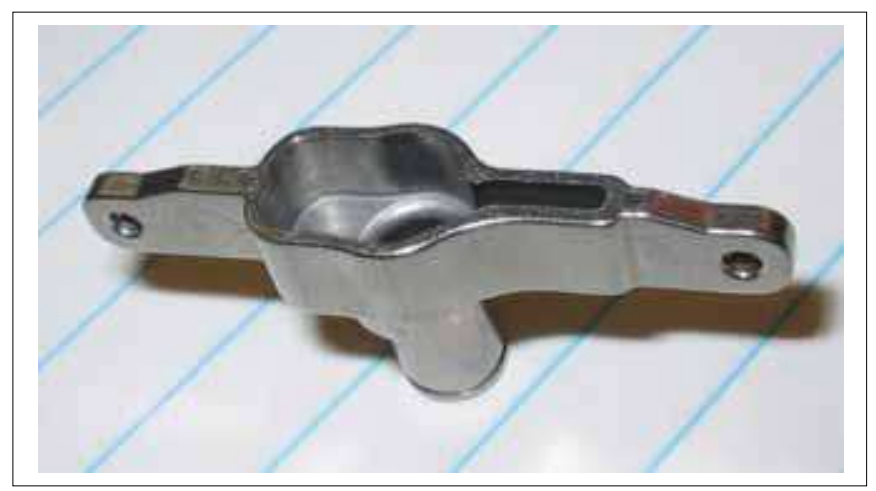

Fig. 1. Design of a PIM part (Schlieper, 2007; courtesy of PIM International).

Further, PIM, as an injection moulding technique, can be adopted to combine different materials via two-component PIM (2C-PIM), production of very small parts via micro PIM $(\mu \mathrm{PIM})$ or using the advantages of gas assisted PIM (GA-PIM). On the other hand, there are several factors still limiting the mass expansion of PIM technology, and tooling and set-up expenses are difficult to justify for low production quantities. According to German (2008), PIM is usually attractive for an annual production of more than 200,000 parts.

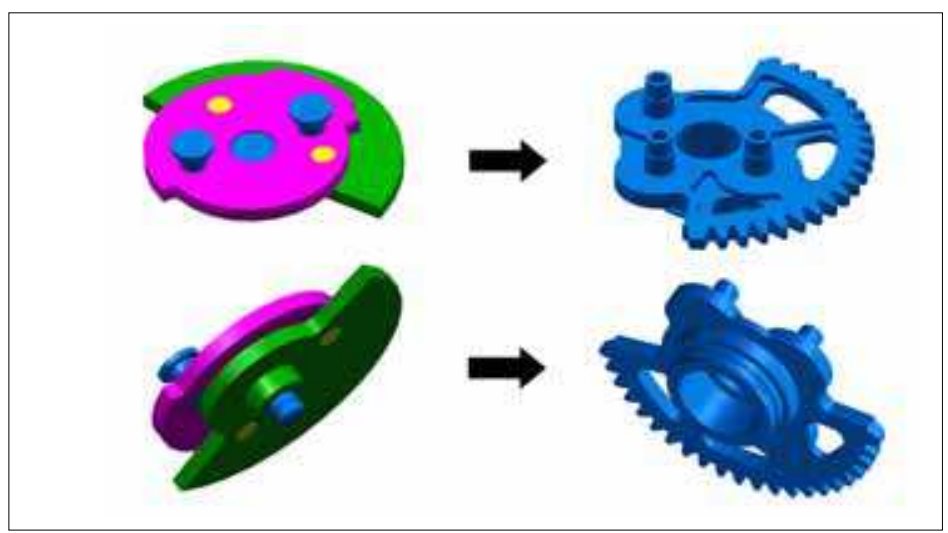

Fig. 2. Demonstration of multiple parts combination into a single PIM item (Schlieper, 2007; courtesy of PIM International). 
The fundamentals of PIM technology have been described in several books (especially German, 1990; German \& Bose, 1997). Within the following text, particular stages of the PIM process - mixing, injection moulding, debinding and sintering - will be briefly introduced, describing the current state-of-the-art and providing some practical information for the producers considering PIM as an alternative route for automotive items. The main focus of this work, however, consists of discussing rheological approaches to control and optimize the mixing and injection moulding steps of the process, because the majority of PIM companies originate from a metallurgical background and not a polymer processing background. Some of the quality issues arising from the moulding step, especially phase separation of powder and binder during mould filling, might cause visual defects, porosity, warpage or even cracks in the final products. Therefore, such quality influencing factor for PIM technology is considered as well, interpreting the latest results of both theoretical and experimental studies.

\section{Description of the process}

The first task to be considered when planning PIM production is to select material - powder and binder. The availability and cost of PIM quality powders are still major limiting factors affecting decision making. Nevertheless, any metal (except for pure aluminium, due to an oxide film on the surface inhibiting sintering) or ceramic powder can be utilized in both PIM divisions (MIM - Metal Injection Moulding and CIM - Ceramic Injection Moulding) if it is prepared in the suitable form. Important powder characteristics such as particle size, particle size distribution and shape of particles are governed by the way of their preparation. New technologies in powder production have been implemented to extend the range of fine metal and ceramic powders for PIM producers (German \& Bose, 1997). An increasing demand motivates powder manufacturers to meet the special requirements of PIM. The ISO TC119 SC5 committee is responsible for MIM materials specifications. A final release of approved specifications is projected for 2011.

The powders used for automotive PIM applications include plain and low alloy steels, high speed steels, stainless steels, super alloys, magnetic alloys and hard metals, and aluminium or zirconium oxides for ceramics. The majority of PIM automotive items, however, are produced from 17-4PH stainless steel. Also, an increased potential has been recently recognized for high Ni content MIM alloys (MECO 26 or 28), which are hot gas corrosion resistant and have better microstructure and mechanical properties than parts made by centrifugal casting (Langer, 2007). MIM316L steel, showing an almost threefold increase in tensile strength and only modest decay in ductility at $-253{ }^{\circ} \mathrm{C}$ compared with room temperature properties, proved to be an excellent candidate for the BMW Hydrogen 7 car (anonym, 2007). GKN Sinter Metal (Germany) produces several hundred tons of MIM parts per year, mainly for automotive industry from Fe-Ni alloys, 42CrMo4, 17-4PH and superalloys for high temperature applications (Schlieper, 2010).

Material component, allowing for the shaping of metal/ceramic powders via injection moulding, is a binder. A typical binder consists of three components: main body, backbone (non-reactive during debinding process, keeping the shape of the part prior to sintering) and additive (German, 1990). Waxes (paraffin, carnauba, microcrystalline, beeswax) in the main body are often combined with the thermoplastic backbone (PE, PP, PS, PA, PMMA, EVA) and stearic or oleic acid. Block copolymers (EVA, EBA, EAA), as they are made of polymer blocks soluble in the dispersion medium and blocks with high affinity to powder, provide 
suitable interactions with powder, imparting steric stabilization of a compound, and thus prevent separation from the powder during the flow. Currently, water-soluble binders based on polyethylene oxide (PEO) are increasingly being employed. Using cemented carbides and a three-component binder (PEO, PMMA, stearic acid) Chuankrerkkul et al. (2008) investigated the effect of the molecular weight of PEO on compound viscosity and discovered that lowering the molecular weight of the PEO did not affect the flow behaviour of the feedstock.

Injection moulding of metal and ceramic powders requires preparing a feedstock, where individual powder particles are fully covered (lubricated) with the smallest effective amount of a binder, Fig. 3. The adjustment of optimum powder/binder ratio within a feedstock is one of the critical tasks during PIM processing and will be discussed in detail in Chapter 3.2.

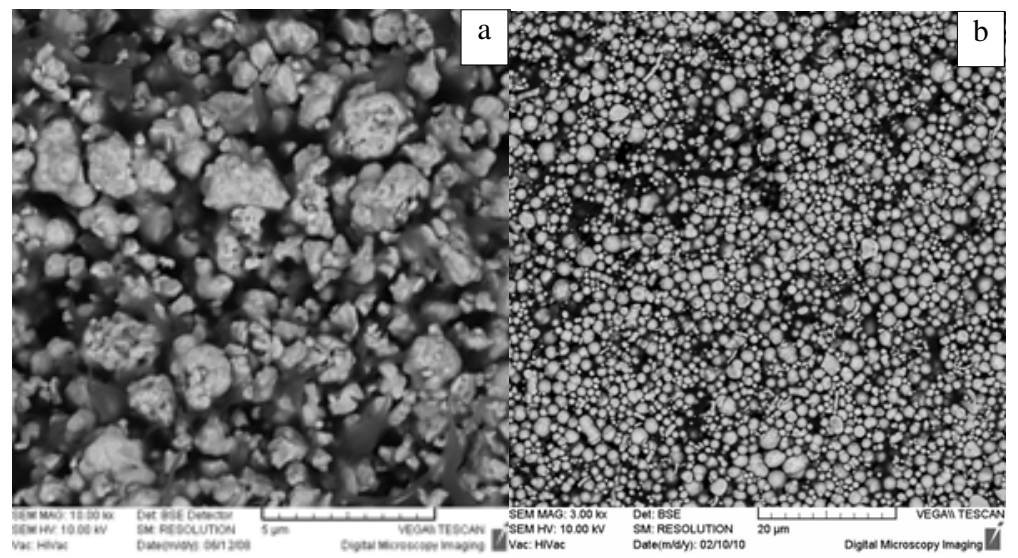

Fig. 3. SEM micrographs of alumina (a) and stainless steel (b) feedstocks.

To ensure precise homogenization, sufficient shear stress is necessary, since PIM powders are rather fine (from 0.1 to $20 \mu \mathrm{m}$ ) with an enhanced tendency towards agglomeration. In this respect, a batch mixing in planetary or Z-blade mixers would be preferred, although usually taking a couple of hours. In a high volume production, twin screw extruders or shear rolls are employed for the feedstock preparation. Nevertheless, a current trend is to buy ready to use (commercial) feedstocks based on a patented binder system mixed with different powders. Perhaps the most widely used is the polyacetal binder Catamold ${ }^{\circledR}$ (BASF), which provides good processability and excellent shape retention. However, its removal is carried out in a highly concentrated nitric acid, and thus its utilization brings enhanced concerns for health and safety regulations. Such an issue can be overcome with water-soluble binders based on polyethylene oxide or polyvinyl alcohol offered by several producers (e.g. Polymer-Chemie, eMBe).

The step during which the feedstock is formed into the desired shape is injection moulding, a technique well known in the automotive industry. Although there is no fundamental difference between injection moulding of PIM compounds and plastics, machines are usually optimized for the processing of powdery materials with a wear-resistant cylinder and screw, and a screw geometry adopted to lower compression rate and extended compression zone compared to standard screws for thermoplastics (Williams, 2008). 
The injection moulding process naturally creates undesirable features such as gate marks, ejector pin marks, or parting lines which must be located in noncritical positions or suppressed after fabrication. Design restrictions include uniform or gradual section thickness changes, minimized wall thickness (reducing not only material consumption and moulding cycle time, but considerably also debinding and sintering), round corners to reduce stress concentrations and risk of fracture, and minimum undercuts on internal bores (Kazmer, 2007; German 2008). Contrary to conventional injection moulding, for PIM it is important (whenever possible) to design items with one flat surface, which allows standard support trays during sintering.

After injection moulding the binder is removed from a green part via chemical, thermal or combined chemical/thermal processes (German, 1990). The choice of debinding method corresponds to the selected binder system. During solvent debinding an immersion of the binder is performed by placing the parts into a solvent (water, ethylene dichloride, nheptane or trichlorethane, e.t.c.) for several hours; alternatively, a solvent vapour, initiating condensation, and subsequently liquid extraction of the binder components is used. If thermal debinding is utilized, the binder is removed through an applied heat. It is carried out, depending on the selected powder, under air, hydrogen, nitrogen or argon atmospheres at various temperatures. Slight and uniform heating (lasting hours, even days) is required in order to withdraw a binder by evaporation or liquid extraction using a wicking material (porous substrate) without disruption of a part.

After the binder removal, the strength of a brown part is to a large extent reduced. Thus, it has to be sintered to the final density, which generally reaches more than $97 \%$ of theoretical (German \& Bose, 1997). Sintering is a technique widely employed in the powder metallurgy. It is carried out at temperatures below the melting point of a powder (usually between 0.6 and 0.9 of the melting temperature) in a sintering furnace in a protective or vacuum atmosphere for metals and an air atmosphere for ceramics. Since an isotropic and uniform sintering shrinkage is required, fine powders, sintering more readily with improved surface finish than coarser powders, are preferred (German \& Bose, 1997). As demonstrated in Fig. 4, defects arising from inhomogeneous mixing evidence themselves on the final sintered parts.

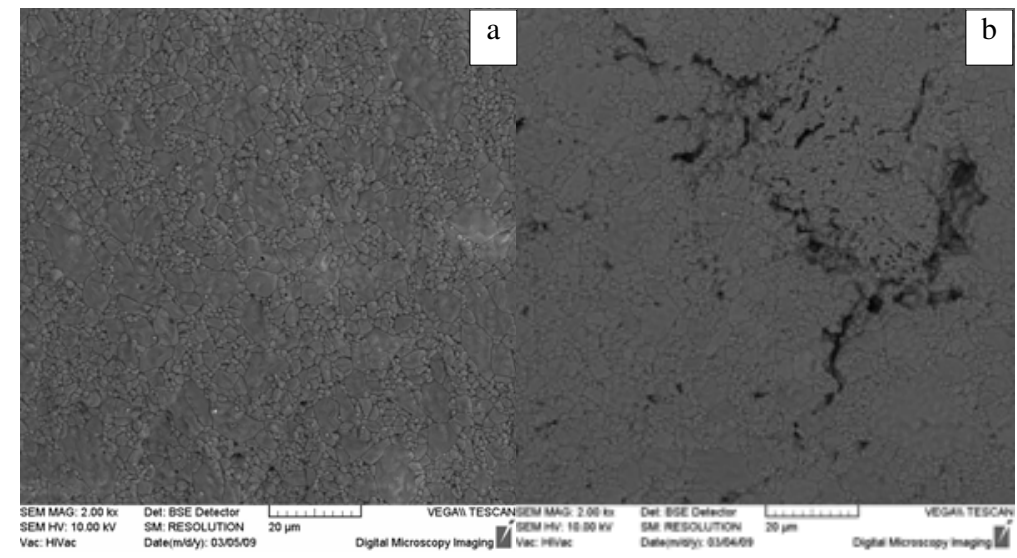

Fig. 4. SEM micrographs of the sintered surface resulting from homogenous (a) and inhomogeneous (b) mixing. 
An important advantage of PIM technology is a possibility of integration of various effects without additional operations. As an example, OBE (Germany) produces watchcases for the Mercedes-Benz AMG from 316L stainless steel with the brushed effect on the surface incorporated in the injection moulding tool, thus, without any finishing (anonym, 2008). Further, as already mentioned in the introduction, PIM allows a combining of metals with ceramics via 2C-PIM, resulting in electric or thermal conductive/insulating, magnetic/nonmagnetic, or ductile/hard items. A crucial aspect of 2C-PIM is the sintering rate control both components must sinter at similar shrinkage, rates and temperatures (Moritz \& Lenk, 2009).

Currently, applications are highly focused to microPIM items having a weight as little as $0.0004 \mathrm{~g}$, thin walls $(20 \mu \mathrm{m})$, aspect ratios up to 20 , structural details in the range of 20-50 $\mu \mathrm{m}$, and surface roughness less than $0.05 \mu \mathrm{m}$. With microPIM additional demands are the size of powders (the grain size of the sintered part must be at least one order of magnitude smaller than the minimum internal dimension of the item) and homogeneity (Moritz \& Lenk, 2009). Finally, a close variant to PIM is powder extrusion moulding used for example in the production of yttrium stabilized zirconia thin walled tubular electrolytes for fuel cells (Jardiel et al., 2009).

\section{Rheological approaches to optimize the process}

\subsection{Binder composition}

Rheology, as a scientific discipline studying material flow properties, represents a powerful tool in the sophisticated treatment of several quality determining factors of the PIM process. For a successful mixing of PIM compounds, the rheological properties of a binder are important when seeking a tailored binder formulation or selecting a proper additive (e.g. Hens et al., 1991; Edirisinghe, 1991; Karatas et al., 2004). As the majority of researchers have concentrated on the effect of binder composition on the rheological properties of feedstocks, the roles of particular binder components and their interrelationships remain unclear. Hsu et al. (1994) compared four kinds of wax - paraffin, polyethylene wax, carnauba and acrawax, serving together with LDPE as a binder for 304L stainless steel. They demonstrated that the latter two waxes exhibited higher viscosity and more suitable pseudoplastic flow, arising from their polar characters (carnauba is alkyl acid ester and acrawax is a secondary amide) forming hydrogen bonds with a metal powder. Hausnerova et al. (2000) studied three types of polymer binders differing in block copolymer used (ethylene-butyl acrylate, ethylene-vinyl acetate, ethylene-acrylic acid). In doing so, they noticed that as the volume concentration of a solid component increased to $30 \mathrm{vol}$. \%, the influence of the particular binder composition on flow properties decreased. Furthermore, Hsu and Lo (1996) employed the McLean-Anderson statistic method (Murray, 1984) to study the fluidity (inverse of viscosity) and pseudoplasticity (in terms of the power-law index) of 15 binder formulations. Their systematic investigation resulted in contour maps demonstrating how fluidity and pseudoplasticity vary with binder components.

Viscosity of a binder should be less than 0.1 Pa.s in order to provide PIM feedstocks with viscosity below $10^{3}$ Pa.s (German, 1990). Thus, researchers must properly select a testing setup for rheological measurements. A capillary rheometry is currently recognized as the best approach to predict the flow behaviour of PIM compounds. This approach, however, is complicated by several factors such as flow restrictions caused by instabilities (Hausnerova et al., 2000) or the so-called Serge-Silberberg effect, i.e. movement of particles from the 
capillary wall to the centre during flow, which achieves a great magnitude, and thus leads to an axial solids concentration gradient (Kubat \& Szalanczi, 1974). In the case of binders, however, a capillary rheometry is difficult to realize due to inherently low viscosity; instead, rotational rheometers of cocylindrical geometry are preferred.

If a steady-state mode of rotational rheometers is employed for concentrated compounds, the material trapped between the plates or cone and plate tends to hang out during measurements (Shenoy, 1999). Further, as reviewed in Hausnerova (2010), the accuracy of using cone and plate rheometers for the measurement of materials prone to wall-slip, secondary flows and temperature changes due to dissipation energy from shear heating should be thoroughly analysed similarly to Kurzbeck et al. (1996). In their work, wall slip was discerned using two geometries according to the Mooney method, secondary flows were accounted for via estimation approaches, where relative torque (ratio of measured torque influenced by secondary flow to a theoretical one under laminar flow) is related to Reynold's number. In the case of the compounds employed in Kurzbeck et al. (1996), the maximum increase of torque due to secondary flows was $0.2 \%$, and an increase of temperature due to dissipation was calculated under adiabatic condition to be $40 \mathrm{~K}$, but the measured values reached less than $1 \mathrm{~K}$.

As pointed out in Hausnerova (2010), interpretations of rheological data of PIM systems often lack the relevant application of corrections necessary to compensate for nonnewtonian flow character. Failure to recognize this fact can lead to errors both in the reporting of reliable data and the comparison of various rheological approaches.

\subsection{Determination of optimal powder/binder ratio}

Optimum powder loading within a feedstock refers to a powder concentration for which a compound exhibits good flow properties (viscosity less than $10^{3}$ Pa.s) as well as homogeneity and stability in the shear rate range of $10^{2}-10^{5} \mathrm{~s}^{-1}$; it should be set $6-14 \%$ lower than a value of maximum powder loading attainable for a given system (Dihoru et al., 2000). There are generally three approaches to determine the maximum powder loading: density measurement, mixing torque evaluation, and rheological tests. Barreiros \& Vieira (2006) proposed an interesting combination of the last two methods employing torque rheometry to determine optimum compositions of PIM feedstocks. The optimum particle loading was determined to be the highest value resulting from the intersections of the adjustment of linear functions of the mixing torque as a function of powder loading plots. Dihoru et al. (2000) demonstrated the possibility of determining optimal solid loading through the aid of neutral network modelling.

Nevertheless, rheological investigation of capillary flow data still represents the most sophisticated evaluation of optimum loading, bearing the relative viscosity (ratio of a feedstock viscosity to the viscosity of a binder) as a variable to obtain maximum packing fraction for a particular powder-binder compound. As a powder concentration reaches the maximum, all of the binder is confined among powder particles, i.e. the flow of the feedstock is restrained, resulting in a sharp increase in relative viscosity.

Clearly, the value of the maximum loading level of a feedstock is influenced by the characteristics of a powder as well as packing procedure. In this respect an ideal PIM powder (German, 1990) should combine large and small particles in a tailored particle size distribution, which provides high packing values. Spherical or rounded shaped powders are preferred due to their easily predictable flow behaviour during mixing with a binder and consequent injection moulding of a feedstock, but the risk of poor shape retention is enhanced. 
According to German (1990) more than a hundred empirical and theoretical relations have been proposed in order to obtain the value of maximum packing fraction from the relative viscosity data. Often a simple empirical Maron-Pierce relation (Maron \& Pierce, 1956) is employed to calculate maximum loading levels for PIM compounds. In cases where the Maron-Pierce model departs from experimental data, its modification, as proposed by German \& Bose (1997), might offer good results, predicting the maximum loading value with high accuracy.

A set of most often recommended relations in the literature (Metzner, 1985; German, 1990) was tested (Honek et al., 2005) on capillary flow data of PIM compounds based on a multicomponent polymer binder (polyethylene, paraffin, ethylene-based copolymers and polyethylene glycol) and three various hard-metal carbide powders. The powders were prepared by milling all components in an inert liquid in a ball mill. The first two powders (UNI 1, UNI 2) had unimodal particle size distribution, while the third powder (BI) had a bimodal one. The shape of the particles was irregular; UNI 1 powder had a smaller aspect ratio of the particles than the two remaining materials.

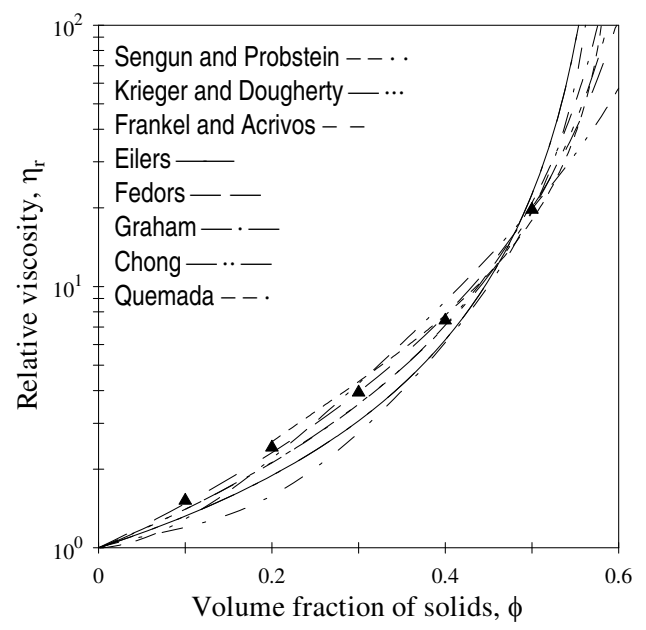

Fig. 5. Relative viscosity data as a function of volume fraction of solids for UNI 1 hard-metal carbide powder; the lines represent mathematical models (Honek et al., 2005).

The fitting of the flow data of the UNI 1 based compounds is depicted in Fig. 5, showing that the fitting curves of the majority of the models lie slightly below the experimental values of relative viscosity. For the UNI 2 compounds the results are even more inconclusive. The irregular shape of particles together with their smaller sizes most probably led to high attractive forces and the formation of a three dimensional network within the compound, and hence to rather enhanced relative viscosities. Thus, the models underestimate the experimental data. The bimodal particle size distribution of BI powder caused a marked decrease of the compound's relative viscosity as compared to UNI 2 data; the Graham model provides the best fit for the experimental data. An agreement between experimental and predicted data in the region of a higher ( $40 \mathrm{vol} \%$ and more) volume fraction of particles might be caused by a closer proximity of the particles, and thus enhanced attractive forces between particles, which lead to a faster build up of the relative viscosity within a higher concentration range. 
Table 1 (Honek et al., 2005) demonstrates on a UNI 1 compound that the predicted values of the maximum volume fraction of the same powder vary with the models applied. Nevertheless, the maximum loading levels determined using relevant models coincide well with the powder characteristics: the highest value of maximum loading ( 0.69 derived from a linearized Mooney model) corresponded to the powder with the broadest distribution of particle sizes (BI), while the lowest value (0.53 from the Frankel-Acrivos model) was attained for powder with a high portion of small particles (UNI 2). This was further supported by rheological measurements (Hausnerova et al., 1999), where compounds containing particles having unimodal particle size distribution showed higher viscosity values at the corresponding shear rates than the bimodal powder (as an example, the flow curve of $40 \mathrm{vol}$. \% UNI compounds coincides with that of 50 vol. \% BI material). It supports the findings of Chang and Powell (1994) and Metzner (1985), which verified that viscosity can be significantly reduced for powders with large differences in size by adding smaller particles, which fill the inter-particle voids, thereby releasing previously immobilised fluid.

\begin{tabular}{|l|c|}
\hline Model & Maximum packing (-) \\
\hline Eilers & 0.60 \\
\hline Chong & 0.60 \\
\hline Fedors & $\mathbf{0 . 6 8}$ \\
\hline Frankel-Acrivos & $\mathbf{0 . 6 0}$ \\
\hline Quemada & $\mathbf{0 . 6 4}$ \\
\hline Graham & 0.58 \\
\hline Krieger - Dougherty & $\mathbf{0 . 6 6}$ \\
\hline Sengun - Probstein & 0.71 \\
\hline
\end{tabular}

Table 1. Maximum packing values for UNI 1 compounds; bold values correspond to the models fitting well with the experimental data (Honek et al., 2005).

\subsection{Flow data relevant for process simulations}

The flow of a feedstock into a mould cavity during injection moulding should be simulated prior to mould construction since some defects such as air traps, dead zones, or weld lines created during moulding cannot be reduced or eliminated during the following debinding and sintering steps. Simulation approaches currently available, built on rheological models describing pseudoplastic flow of polymer melts, might be successfully used for uncomplicated PIM items, providing information e.g. about the stress concentrations' zones as demonstrated on Fig. 6, on which basis the part design can be optimized.

Nevertheless, in order to embody more stringent flow situations, the software should be adopted to the rheological specifics of PIM compounds to produce non-defect parts. This implies that at first, the rheological parameters of PIM feedstocks have to be known with sufficient accuracy, and second, that the rheological model has to be developed to describe the specific flow features as those reported e.g. for a very fine aluminium oxide powder mixed with commercially available binder (Hausnerova et al., 2010a). The viscosity of this feedstock (60 vol. \%) decreased with increasing shear rate only up to $500 \mathrm{~s}^{-1}$, suggesting particle or binder molecule orientation and ordering with flow. As the shear rate was further 
increased, shear thinning turned into a dilatant flow, indicating that particles could not form layers and slide over each other (flow cause firstly reported by Hoffman (1972). In addition, for the alumina feedstock investigated (Hausnerova et al., 2010a) such structure restructuralization appeared repeatedly, i.e. the flow changed from pseudoplastic to dilatant and back to pseudoplastic, implying a failure of the rheological models currently available.

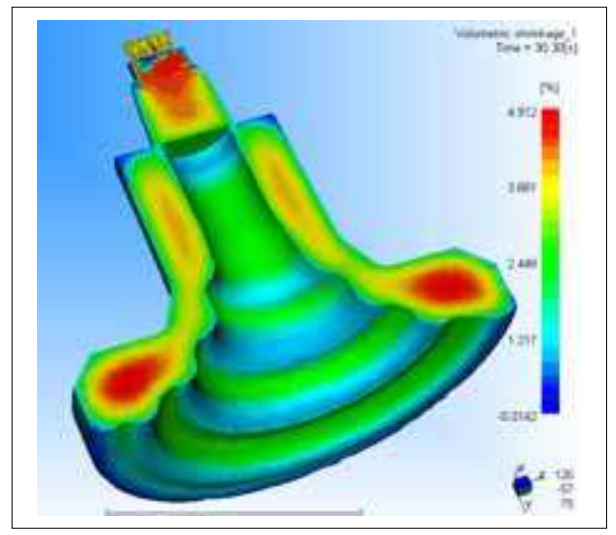

Fig. 6. A MoldFlow simulation of the PIM mould filling.

Rheological data of PIM compounds should be studied not only as a function of shear rate (stress), but also as a variable of processing conditions - temperature and pressure. Temperature sensitivity of PIM compounds can be accounted for via activation energy of shear flow. German (1990) suggests an increase of activation energy with increasing filler content. His idea is based on the explanation that the relative rate of viscosity decrease is typically faster in the loaded system due to the superimposed change in a volume fraction of powder associated with a difference in thermal expansion coefficients of powder and binder. On the other hand, Shenoy (1999) proposes an opposite dependence of activation energy on powder content; the viscosity of a compound is less temperature sensitive as compared to a binder viscosity, because powder provides very little free volume change with temperature in relation to a binder.

To confirm one of the two mechanisms presented, temperature effect on the flow properties of PIM materials on compounds based on a hard-metal carbide powder in a thermoplastic binder (polyethylene, ethylene butyl acrylate block copolymer and paraffin) in a broad temperature range $\left(140-200{ }^{\circ} \mathrm{C}\right)$ on a capillary rheometer have been investigated (Honek et al., 2002). Activation energy was calculated using the Arrhenius relation, which was found to be valid for PIM compounds only in the stable flow region (without evidence of pressure oscillations). It should be mentioned that the temperature effect reported (Honek et al., 2002) was studied with specific regard to the flow instabilities accompanying the flow of PIM compounds, which has apparently not been reported heretofore.

The activation energy of carbide compounds decreased with powder content, indicating a decay of the sensitivity of a compound to temperature changes. Hausnerova et al. (2009), employed another approach to determine temperature sensitivity of PIM compounds and reached the same conclusion. Very recently, Contreras et al. (2010) broaden this finding for a set of three bronze and four Inconel 718 powders. According to their observation, activation 
energy diminishes with increasing powder content up to the optimum powder loading of the particular compound, while for feedstocks exceeding optimum loading, the activation energy becomes enhanced. Thus, the evaluation of activation energy might serve as a simple method to determine an optimum loading level of powder of a PIM feedstock as discussed in Chapter 3.2.

In spite of the fact that pressure might alter the viscosity of many materials significantly, it is a parameter disregarded in simulation approaches, mainly due to the lack of reliable data caused by ambiguous definitions of pressure sensitivity coefficients, various evaluation techniques and test artefacts connected. It is only accounted for through pressure-volumetemperature (PVT) characteristics employed to predict a holding pressure during moulding (Greene \& Heaney, 2007) or shrinkage of final parts (Laddha et al., 2009). PVT data measurements of PIM materials are reported scarcely (Wie et al., 2000; Greene \& Heaney, 2007; Laddha et al., 2009; Persson et al., 2009).

The evaluation methods of a viscosity's sensitivity to pressure are direct -experimental, and indirect - analysis and/or correlation to other properties (described in detail in Hausnerova et al., 2006). The first group concerns double piston rheometers, or single piston rheometers modified by a secondary chamber located downstream of a capillary. An indirect evaluation is based mainly on calculations from Bagley plots (Duvdevani \& Klein, 1967) intercepting non-linearities in the pressure profiles (capillary and slit) or from the relationship between viscosity and free volume (Utracki, 1985; Sedlacek et al., 2005). Goubert et al. (2001) compared Utracki's approach, calculations from Bagley plots and measurements on a modified single piston rheometer, and proved the reliability of the last mentioned method. In a series of papers (Hausnerova et al., 2006; 2009; 2010b) the direct measurement of the pressure influence on the flow properties using this technique was applied on cemented carbide compounds. A single piston rheometer was modified (Polymer Centre, TBU in Zlin) with an additional device generating backpressure, thus enhancing pressure actuating on a tested melt (Sedlacek et al., 2004). It consists of a chamber with a restricting needle valve moving horizontally by means of a screw thread in order to set the level of pressurization applied on the material during its flow through the die. The Carreau-Yasuda model (Yasuda, 1981) was employed to fit the experimental data of temperature and pressure dependent shear viscosity.

German (1990) stated that sensitivity to pressure should decrease with a loading level of powder in a PIM compound. This was confirmed for the low to moderate (up to 30 vol. \%) powder concentrations in Hausnerova et al. (2006). However, at higher loading levels (50 vol. \%), the sensitivity to pressure seems to be enhanced in comparison to a pure polymer binder (Hausnerova et al., 2009). It can be speculated that the compressibility of a structure formed within interacting particles becomes important at a high loading level, while for low to moderate concentrations the pressure sensitivity is governed predominantly by a polymer binder. The mechanism of viscosity dependency pressure is not yet clarified, although for PIM compounds it is supposed to vary with the characteristic (particle size and particle size distribution) of powder used.

In Hausnerova et al. (2010b), three types of PIM compounds, differing in their particle size distributions and mean diameters of particles, have been considered with the conclusions supporting the idea of altering a compound's pressure sensitivity via the tailoring of powder characteristics. The highest pressure sensitivity coefficient $\left(32.9 \mathrm{GPa}^{-1}\right)$ was found for a feedstock containing broad particle size distributed powder having a perceptible portion of small particles. It implies the coexistence of the two mechanisms. First, at low to 
moderate loading levels the pressure sensitivity of the compounds is governed by the sensitivity of a binder component, which is connected to the free volume changes as recently shown by Sedlacek et al. (2005), and diminishes as powder concentration increases. Second, at high powder loading the driving factor is the compressibility of the powder itself related to the (re)organization of the particles within the melt during pressurization.

Finally, it should be noted that the temperature sensitivity of a carbide compound does not vary significantly with pressure (revealing the value $(18.4 \pm 0.7) 10^{-3}{ }^{\circ} \mathrm{C}^{-1}$ for pressures up to $50 \mathrm{MPa}$ ), in contrast to the pure binder, the temperature sensitivity coefficient of which is a linear increasing (from $18.810^{-3}{ }^{\circ} \mathrm{C}^{-1}$ at ambient pressure to $59.410^{-3}{ }^{\circ} \mathrm{C}^{-1}$ at $50 \mathrm{MPa}$ ) function of pressure.

\subsection{Quantifying quality issues through rheological approaches}

A portion of sintered parts, which do not reach the quality requirements, might in some instances achieve up to $25 \%$ (Williams, 2009). If a major quality influencing issue appearing during injection moulding - a separation of binder from the feedstock, could be recognized prior to debinding and sintering steps, material, energy and time would be saved. The mechanism of a phase separation is still not fully understood much like its onset and extent is not quantified.

Recently, Thornagel (2009) demonstrated that local shear rate gradients force powder particles to leave areas of high gradients, thus making them the trigger for phase separation. Assuming no slip condition, i.e. good adhesion of the feedstock to the wall of the channel, a significant shear rate peak occurs close to the wall, while the middle of the flow domain is characterised with a plateau at a much lower shear rate level.

Particles flowing in the peak area close to the wall then experience a non-uniform shear rate leading to rotation, which increases in severity as the shear stress gradients increase. Rotating particles naturally move away from areas of high shear gradients (Fig. 7). As a result, the area of the highest shear rate is characterized by high binder content, while the plateau of the lower shear rate accommodates a powder rich material. To predict the situation in which a separation pattern changes continuously during moulding would require a multi-phase simulation, taking into account the particular feedstock components.

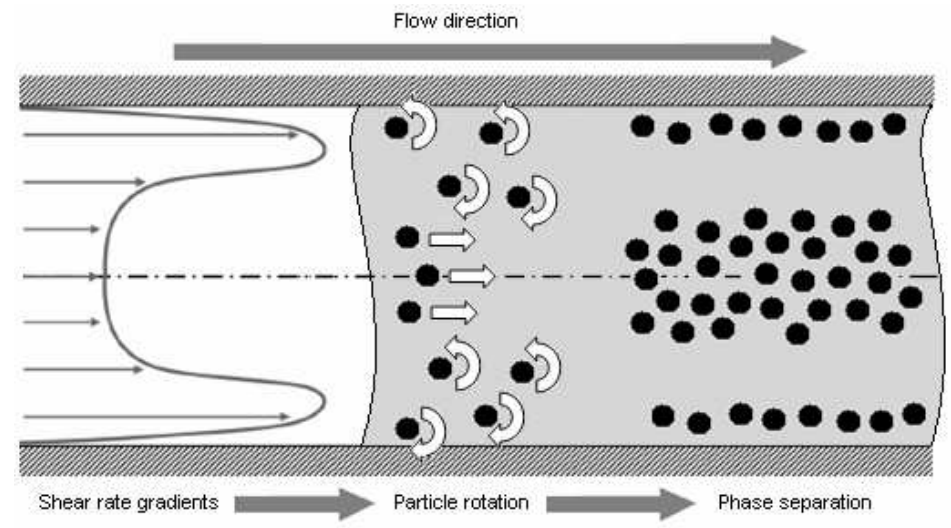

Fig. 7. Flow pattern of PIM feedstock across the channel causing powder - binder separation as proposed by Thornagel (2009). 
Instead, Thornagel (2009) proposes a simplified simulation, modelling the feedstock as a bulk and extending the currently popular 3D Navier Stokes equations in a way that powder and binder concentrations and their variations can be predicted depending on shear rate history. If validated, such an approach might be a breakthrough in PIM computer aided support.

In another approach Jenni et al. $(2008 ; 2009)$ used a software simulation based on the balance model of the flow of rigid, spherical particles in a Newtonian fluid to compare the influence of injection moulding parameters on separation appearance. A differential scanning calorimeter (DSC) was selected to quantify the local powder content. To compare different materials and processing parameters used for injection moulding, three testing moulds were used, as schematically demonstrated in Fig. 8.
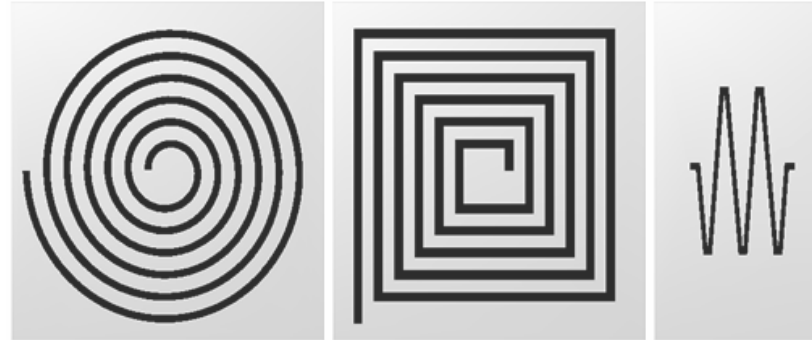

Fig. 8. Spiral, square spiral and zig-zag designs of a testing mould.

The experiments incorporated dependent parameters for mouldability - flow length and input variables (nozzle and mould temperatures and injection speed). In cavity geometry, it has been demonstrated that powder content decreases to some extent as the number of corners increases.

To quantify the separation, the results from the software simulation using the balance model were compared with experimental findings obtained using radiography, computer tomography and DSC. The authors (Jenni et al., 2008) demonstrated that the balance model clearly portrays the migration of particles for simple geometries, but irregularities in the feedstock flow, such as slip effects at the wall and the fountain flow, are not taken into account by this model.

The testing moulds depicted in Fig. 8 only partly fulfill the purpose of forcing phase separation during mould filling. Thus, a mould (developed in cooperation between TBU in Zlin and IFAM, Bremen) including inner and outer corners, radical thickness changes, weldlines and a thin film part was recently constructed in order to investigate the separation development during mould filling, Fig. 9.

SEM analysis of the particular cross sections derived from this testing mould (Fig.10), combined with EDX analysis of the distribution of the elements typical for powder and binder, then provides a quantitative evaluation of the powder-binder separation (Hausnerova et al., 2010c).

The next step is a rheological/simulation approach directly linking the factors responsible for powder-binder separation during injection moulding to the quantified defects appearing on final sintered products. In this respect, a wall slip phenomenon could be considered as a qualitative parameter indicating powder-binder separation absence/occurrence, because it represents an often used practical approach to avoid powder-binder separation by setting up conditions under which a compound flows as a plug, i.e. slips at the wall. 


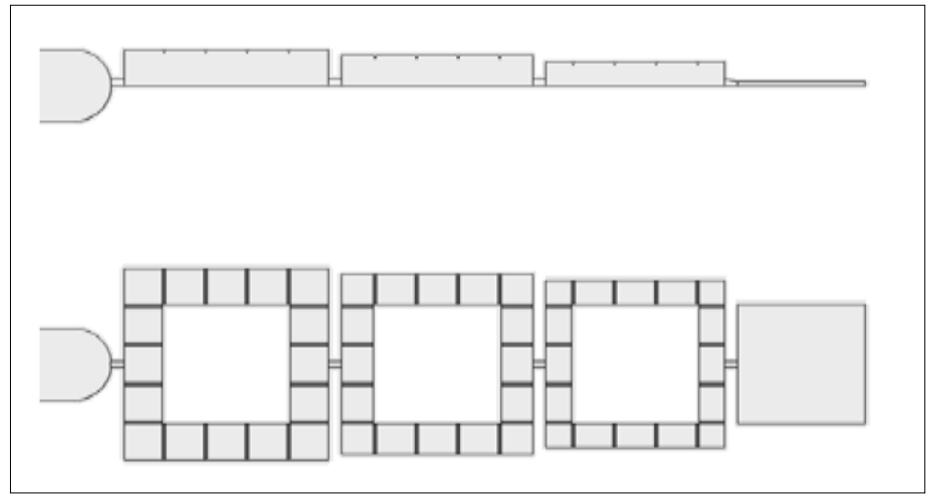

Fig. 9. Design of a mould testing powder-binder separation (Community Design 001704974, Tomas Bata University in Zlin)

The conditions at which a material slips at the wall depend on material characteristics such as the type of powder and polymer binder, the size and particle size distribution of the powder, the concentration of the powder and its surface treatment as well as on processing parameters such as temperature, pressure, and shear rate, and most important, on the microscopic nature of the channel wall. The last mentioned parameter is, however, different during processing and rheo-testing. Thus, a rheometer should be modified accordingly. It is believed that implementing recently acquired knowledge into existing simulation software will lead to the production of defect-free items.

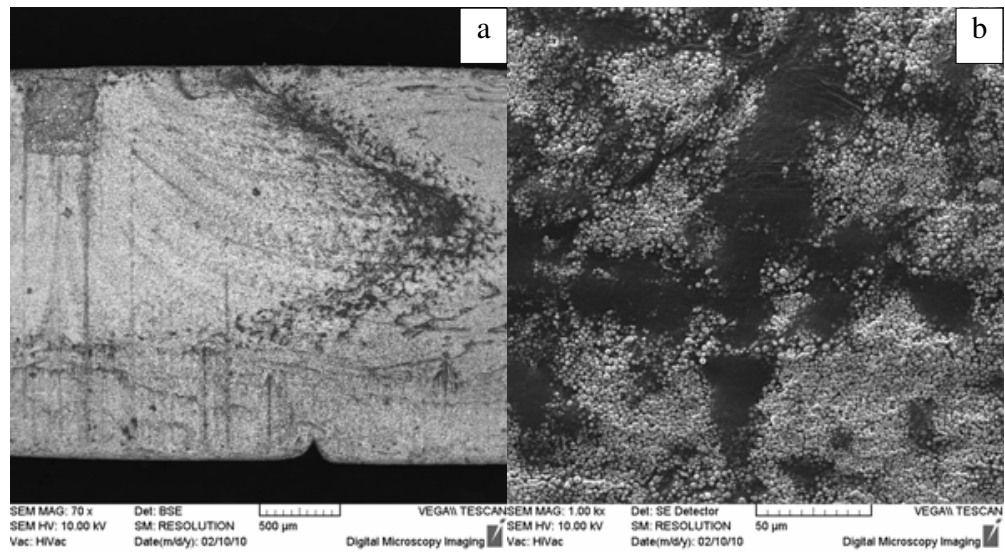

Fig. 10. Flow pattern of powder-binder separation (a) and detail of separated binder area (b).

\section{Conclusion}

Still widely considered a new technology, PIM constitutes an ongoing topic of both commercial and scientific interest. As an effective processing route (high added value), it represents an interesting production method for automotive items, especially in an economic downturn periods. 
As a developing technology, PIM has many quality determining issues to be dealt with. The quality of PIM products is usually tested after the final, sintering step, however, the defects might arise during previous stages - mixing, moulding, and debinding.

Rheology could play a role of considerable importance in controlling and optimizing the PIM process and eliminating some critical quality concerns. At present, the potential of rheological models available to describe the peculiarities of the flow behaviour of PIM compounds is rather limited as these models are not established for multiphase systems containing several binder components and powders of irregular shape, broad distribution of particle sizes and sizes with enhanced tendency to form agglomerates. Therefore, the challenging task for the current research is to design a model validated on reliable flow data conducted considering the structural changes of PIM compounds upon shearing, and its implementation into the approaches simulating the flow of the PIM feedstocks.

\section{Acknowledgments}

This work has been financially supported by the Ministry of Education, Youth and Sports of the Czech Republic (Project No. MSM 7088352101). Lukáš Jiránek (Tomas Bata University in Zlin) is gratefully acknowledged for creating the schematic figures.

\section{References}

anonym (2007). MIM 316L stainless seeks applications in BMW Hydrogen 7 car. PIM International, 1, 4, 5, ISSN 1753-1497

anonym (2008). Clock casing for luxury automotive applications. PIM International, 2, 4, 29, ISSN 1753-1497

anonym (2010). MIM sales set to rebound in Japan after falls in 2008 and 2009. PIM International, 4, 1, 10, ISSN 1753-1497

Barreiros, F. M. \& Vieira, M. T. (2006). PIM of non-conventional particles. Ceramics International, 32, 3, 297-302, ISSN 0272-8842

Contreras, J. M.; Jimenez-Morales, A. \& Torralba, J. M. (2010). Experimental and theoretical methods for optimal solids loading calculation in MIM feedstocks fabricated from powders with different particle characteristics. Powder Metallurgy, 53, 1, 34-40, ISSN 0032-5899

Chang, C. \& Powell, R.L. (1994). Effect of particle size distributions on the rheology of concentrated bimodal suspensions. eburnal of Rheology, 38, 1, 85-98, ISSN 0148-6055

Chuankrerkkul, N.; Messer, P. F. \& Davies, H. A. (2008). Flow and void formation in powder injection moulding feedstocks made with PEG/PMMA binders. Part 1 Experimental observations. Powder Metallurgy, 51, 1, 66-71, ISSN 0032-5899

Dihoru, L. V.; Smith, L. N. \& German R. M. (2000). Experimental analysis and neural network modeling of the rheological behaviour of powder injection moulding feedstocks formed with bimodal powder mixtures. Powder Metallurgy, 43, 1, 31-36, ISSN 0032-5899

Duvdevani, J. \& Klein, I. (1967). Analysis of polymer melt flow in capillaries including pressure effects. SPE eburnal, 23, 41-45, ISSN 1086-055X

Edirisinghe, M. J. (1991). The effect of processing additives on the properties of a ceramicpolymer formulation. Ceramics International, 17, 2, 89-96, ISSN 0272-8842 
Goubert, A.; Vermant, J.; Moldenaers, P.; Göttfert, A. \& Ernst, B. (2001). Comparison of measurement techniques for evaluating the pressure dependence of the viscosity. Applied Rheology, 11, 1, 26-37, ISSN 1430-6395

German, R. M. (1990). Powder Injection Moulding. Metal Powder Industries Federation, ISBN 978-0918404954, Princeton

German, R. M. \& Bose, A. (1997). Injection Moulding of Metals and Ceramics. Metal Powder Industries Federation, ISBN 978-1878954619, Princeton

German, R.M. (2007). Inverse approach to optimizing MIM shape/size. PIM International, 1, 4, 37-38, ISSN 1753-1497

German, R. M. (2008). Designing for metal injection moulding: a guide for designers and end-users. PIM International, 2, 4, 17-25, ISSN 1753-1497

Greene, C. D. \& Heaney, D.F. (2007). The PVT effect on the final sintered dimensions of powder injection molded components. Materials \& Design, 28, 1, 95-100, ISSN 02613069

Hausnerova, B.; Saha P. \& Kubat, J. (1999). Capillary flow of hard-metal carbide powder compounds, International Polymer Processing, 14, 3, 254-260, ISSN 0930-777X

Hausnerova, B.; Saha, P.; Kubat, J.; Kitano, T. \& Becker, J. (2000). Rheological behaviour of hard-metal carbide powder suspensions at high shear rates. eburnal of Polymer Engineering, 20, 4, 237-265, ISSN 0250-8079

Hausnerova, B.; Sedlacek, T.; Slezak, R. \& Saha, P. (2006). Pressure-dependent viscosity of powder injection moulding compounds, Rheologica Acta, 45, 3, 290-296, ISSN 00354511

Hausnerova, B.; Sedlacek, T. \& Vltavska, P. (2009). Pressure-affected flow properties of powder injection moulding compounds. Powder Technology, 194, 3, 192-196, ISSN 0032-5910

Hausnerova, B. (2010). Rheological characterization of powder injection moulding compounds. Polimery, 55, 1, 3-11, ISSN 0032-2725

Hausnerova, B.; Marcanikova, L.; Filip, P. \& Saha, P. (2010a). Optimization of powder injection molding of feedstock based on aluminium oxide and multicomponent water-soluble polymer binder. Polymer Engineering and Science, submitted

Hausnerova, B.; Sedláček, T.; Filip, P. \& Saha, P. (2010b). Rheological properties of powder injection moulding compounds at elevated pressures. Powder Technology, submitted

Hausnerova, B.; Marcanikova, L.; Filip, P. \& Saha P. (2010c). Wall-slip velocity as a quantitative measure of powder-binder separation during powder injection moulding, Proceeding of PM2010, Firenze, October 2010, accepted

Hens, J.; Lee, D. \& German R. M. (1991). Integrity of complex shape products by powder injection molding, Powder Metallurgy, 23, 1, 15-21, ISSN 0032-5899

Hoffman, R. L. (1972). Discontinuous and dilatant viscosity behavior in concentrated suspensions. I. Observation of a flow instability. Transactions of the Society of Rheology, 16, 1, 155-173, ISSN 0038-0032

Honek, T.; Hausnerova, B. \& Saha, P. (2002). Temperature dependent flow instabilities of highly filled polymer compounds. Applied Rheology, 12, 2, 72-80, ISSN 1430-6395

Honek, T.; Hausnerova, B. \& Saha, P. (2005). Relative viscosity models and their application to capillary flow data of highly filled hard-metal carbide powder compounds. Polymer Composites, 26, 1, 29-36, ISSN 0272-8397 
Hsu, K. C.; Lin, C. C. \& Lo, G. M. (1994). Effect of wax composition on injection moulding of 304L stainless steel powder. Powder Metallurgy, 37, 4, 272-276, ISSN 0032-5899

Hsu, K. C. \& Lo, G. M. (1996). Effect of binder composition on rheology of iron powder injection moulding feedstocks: experimental design. Powder Metallurgy, 39, 4, 286289, ISSN 0032-5899

Jardiel, T.; Levenfelf, B.; Jimenez, R. \& Varez, A. (2009). Fabrication of 8-YSZ thin-wall tubes by powder extrusion moulding for SOFC electrolytes. Ceramics International, 35, 6, 2329-2335, ISSN 0272-8842

Jenni, M.; Schimmer, L.; Zauner, R.; Stampfl, J. \& Morris, J. (2008). Quantitative study of powder binder of feedstocks. PIM International, 2, 4, 50-55, ISSN 1753-1497

Jenni, M.; Zauner, R. \& Stampfl, J. (2009). Measurement methods for powder binder separation in PIM components. Proceedings of EURO PM 2009, 2, 141-146, ISBN 9781899072071, Copenhagen, October 2009, European Powder Metallurgy Association

Karatas, C.; Kocer, A.; Ünal, H. I. \& Saritas, S. (2004). Rheological properties of feedstock prepared with steatite powder and polyethylene-based thermoplastic binders. eburnal of Materials Processing Technology, 152, 77-83, ISSN 0924-0136

Kazmer, D. O. (2007). Injection Mould Design Engineering, Hanser Gardner Publications, ISBN 978-1569904170, Cincinnati

Kearns, M. (2009). European MIM status. Proceedings of PIM 2009 International Conference on Powder Injection Molding, Orlando, March 2009, Metal Powder Industries Federation

Kubat, J. \& Szalanczi, A. (1974). Polymer-glass separation in the spiral mold test. Polymer Engineering and Science, 14, 12, 873-877, ISSN 0032-3888

Kurzbeck, S.; Kaschta, J. \& Münstedt, H. (1996). Rheological behaviour of a filled wax system. Rheologica Acta, 35, 5, 446-457, ISSN 0035-4511

Laddha, S.; Wu, C.; Vallury, S.; Lingam, G.; Lee, S.; Simmons, K.; Thomas, P.; Levenfeld, B.; Varez, A.; Park, S.J.; Ahn, S.; German, R.M. \& Atre, S.V. (2009). Characterisation of alumina feedstock with polyacetal and wax-polymer binder systems for micro powder injection moulding ( $\mu$ PIM). PIM International, 3, 3, 64-70, ISSN 1753-1497

Langer I. (2007). Schunk builds on designing successful automotive MIM parts. PIM International, 1, 4, 39, ISSN 1753-1497

Li Y. (2007). Demand for precision components set to drive Chinese PIM manufacturing into the mainstream. PIM International, 1, 4, 17-25, ISSN 1753-1497

Maron, S. H. \& Pierce, P. E. (1956). Application of Ree-Eyring generalized from theory to suspensions of spherical particles. eburnal of Colloid Science, 11, 80-95, ISSN 00958522

Metzner A. B. (1985). Rheology of suspensions in polymeric liquids. eburnal of Rheology, 29, 6, 739-775, ISSN 0148-6055

Moritz, T. (2008). Two-component CIM parts for the automotive and railway sectors. PIM International, 2, 4, 38-39, ISSN 1753-1497

Moritz, T. \& Lenk, R. (2009). Ceramic injection moulding: a review of developments in production technology, materials and applications. PIM International, 3, 3, 23-34, ISSN 1753-1497

Murray, J.S. Jr. (1984). X-Stat statistical experiment design/data analysis/nonlinear optimization, John Wiley\& Sons, ISBN 978-0471524441, New York 
Persson, H.; Hausnerova, B.; Nyborg, L. \& Rigdahl, M. (2009). Rheological and thermal properties of a model system for PIM. International Polymer Processing, 24, 2, 206212, ISSN 0930-777X

Schlieper, G. (2007). Leading German manufacturer works to develop the market for MIM in automotive sector. PIM International, 1, 3, 37-41, ISSN 1753-1497

Schlieper, G. (2010). Global PM leader GKN Sinter Metals optimistic as MIM gains acceptance with end-users. PIM International, 1, 4, 44-46, ISSN 1753-1497

Sedlacek, T.; Zatloukal, M.; Filip, P.; Saha, P. \& Boldizar, A. (2004). On the effect of pressure on the shear and elongational viscosities of polymer melts. Polymer Engineering and Science, 44, 7, 1328-1337, ISSN 0032-3888

Sedlacek, T.; Cermak, R.; Hausnerova, B.; Zatloukal, M.; Boldizar, A. \& Saha, P. (2005). On pvt and rheological measurements of polymer melts: correction of the hole fractionviscosity relationship. International Polymer Processing, 20, 3, 286-295, ISSN 0930$777 \mathrm{X}$

Shenoy, A.V. (1999). Rheology of Filled Polymer Systems, Kluwer Academic Publishers, ISBN 0412-83100-7, Dordrecht

Thornagel, M. (2009). MIM-simulation: A virtual study on phase separation, Proceedings of EURO PM 2009, 2, 135-140, ISBN 978-1899072071, Copenhagen, October 2009, European Powder Metallurgy Association

Utracki, L.A. (1985). A method of computation of the pressure effect on melt viscosity. Polymer Engineering and Science, 25, 655-668, ISSN 0032-3888

Wie, W.C.J.; Wu, R.Y. \& Ho, S.J. (2000). Effects of pressure parameters on alumina made by powder injection moulding. eburnal of the European Ceramic Society, 20, 9, 1301-1310, ISSN 0955-2219

Williams, N. (2008). Arburg sets the pace in the production of moulding machines for PIM. PIM International, 2, 3, 49-52, ISSN 1753-1497

Williams, N. (2009). Fraunhofer IFAM: A commitment to industry oriented research helps drive MIM product development. PIM International, 3, 3, 51-56, ISSN 1753-1497

Yasuda, K.; Armstrong, R.C. \& Cohen, R.E. (1981). Shear flow properties of concentrated solutions of linear and star branched polystyrenes, Rheologica Acta, 20, 2, 163-178, ISSN 0035-4511 


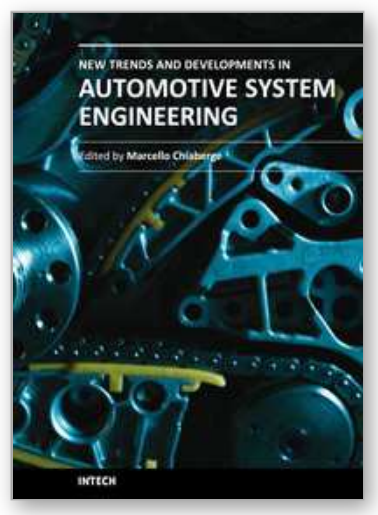

\author{
New Trends and Developments in Automotive System Engineering \\ Edited by Prof. Marcello Chiaberge
}

ISBN 978-953-307-517-4

Hard cover, 664 pages

Publisher InTech

Published online 08, January, 2011

Published in print edition January, 2011

In the last few years the automobile design process is required to become more responsible and responsibly related to environmental needs. Basing the automotive design not only on the appearance, the visual appearance of the vehicle needs to be thought together and deeply integrated with the â€œpowerâ€ developed by the engine. The purpose of this book is to try to present the new technologies development scenario, and not to give any indication about the direction that should be given to the research in this complex and multi-disciplinary challenging field.

\title{
How to reference
}

In order to correctly reference this scholarly work, feel free to copy and paste the following:

Berenika Hausnerova (2011). Powder Injection Moulding - An Alternative Processing Method for Automotive Items, New Trends and Developments in Automotive System Engineering, Prof. Marcello Chiaberge (Ed.), ISBN: 978-953-307-517-4, InTech, Available from: http://www.intechopen.com/books/new-trends-anddevelopments-in-automotive-system-engineering/powder-injection-moulding-an-alternative-processingmethod-for-automotive-items

\section{INTECH}

open science | open minds

\section{InTech Europe}

University Campus STeP Ri

Slavka Krautzeka 83/A

51000 Rijeka, Croatia

Phone: +385 (51) 770447

Fax: +385 (51) 686166

www.intechopen.com

\section{InTech China}

Unit 405, Office Block, Hotel Equatorial Shanghai

No.65, Yan An Road (West), Shanghai, 200040, China

中国上海市延安西路65号上海国际贵都大饭店办公楼405单元

Phone: +86-21-62489820

Fax: +86-21-62489821 
(C) 2011 The Author(s). Licensee IntechOpen. This chapter is distributed under the terms of the Creative Commons Attribution-NonCommercialShareAlike-3.0 License, which permits use, distribution and reproduction for non-commercial purposes, provided the original is properly cited and derivative works building on this content are distributed under the same license. 